\title{
Systems modelling to support the complex nature of healthcare services
}

\author{
Per Engelseth ${ }^{1}$ (D) B. E. White ${ }^{2} \cdot$ Ingunn Mundal ${ }^{3} \cdot$ Trude Fløystad Eines $^{3} \cdot$ Duangpun Kritchanchai $^{4}$
}

Received: 23 July 2020 / Accepted: 29 October 2020 / Published online: 16 December 2020

(c) The Author(s) 2020

\begin{abstract}
Healthcare is a service commonly associated with lacking performance in relation to output and the economy of production. Contingency theory and complex systems thinking are approaches here combined to study the logistics of healthcare service flows. Contingency theory directs attention to networked interdependencies while complex systems thinking concerns process emergence and flexible resource use in supporting logistics. This hybrid form of analysis gives conceptual direction to information technology development and use to support the logistics of healthcare services. Three small examples of healthcare service as logistics processes in their as-is state are provided and analysed based on the developed analytical framework. These illustrate in detail what exemplifies complexity in this industry. Given the inherently complex nature of many types of healthcare services, this discussion concerns how to conceptually model information systems in healthcare services as a complex system. This chosen complexity-sensitive approach of service logistics constitutes a basis for information technology enabled healthcare service development sensitive to this type of service provision directing focus to the emergent features of healthcare service needs. It is also a basis for further investigation into this topic of information technology use to support the inherent logistical complexity of healthcare services.
\end{abstract}

Keywords Healthcare services · Service logistics $\cdot$ Systems modelling · Information systems · Interdependencies · Contingency theory $\cdot$ Case study

$\begin{array}{ll}\text { Abbreviations } \\ \text { BD } & \text { Big data } \\ \text { EMT } & \text { Emergency medical technician } \\ \text { GP } & \text { General practitioner } \\ \text { IoT } & \text { Internet of things } \\ \text { IPD } & \text { Inpatient department } \\ \text { IS } & \text { Information systems } \\ \text { IT } & \text { Information technology } \\ \text { ODP } & \text { Outpatient department } \\ \text { PO } & \text { Purchasing order }\end{array}$

Per Engelseth

pen008@uit.no

University of Troms $\varnothing$, Narvik Campus, Norway

2 Complexity Are Us Systems Engineering Strategies, Sudbury, MA, USA

3 Department of Health and Social Care, Molde University College, Molde, Norway

4 Faculty of Engineering, Mahidol University, Nakhon Prathom, Thailand
PR Purchasing request

SCM Supply chain management

\section{Background}

\subsection{Background}

Contemporary management of healthcare services involves using large amounts of time and resources. Healthcare management normally follows a predominant deterministic approach. This means that detailed planning visible as more or less rudimentary budgets based on historical data leave practitioners having to solve operational medical issues as they arise based on intuition combined with use of often archaic and difficult to use computer software. Given the lack of time most healthcare practitioners have in their practice, learning to develop healthcare service is mainly found as trial and error cognitive processes. Healthcare services vary greatly in their predictability. They always have some degree of uncertainty associated with them. Then this ad-hoc scenario at healthcare institutions and in the increasing use 
of home treatment of patients can hardly be characterised as logistically optimal. Healthcare service involves logistics to support the treatment of patients through the timely provision of goods, people, and tools to appropriate locations in healthcare facilities [1]. Research has shown that this form of service provision has shortcomings in current healthcare efforts which include quality of process coordination, treatment cycle time, inventory management, and information management infrastructure practices [1-5]. This study calls attention to how information systems (ISs) support healthcare services with focus on sensitivity on the particularities of this form of logistical production. Here we step out of the daily challenges of the healthcare practitioners and provide conceptual rethinking on the logistics of healthcare serves as a complex phenomenon that demand in practices appropriate information systems to support this characteristic of being veiled in uncertainty.

Healthcare is a member of the services industry where information is critical in supporting the particularities of the service. Therefore, the first step is to identify healthcare particularities that impact IS development to support healthcare logistics. These particularities are evoked through a combined use of contingency theory [6] pointing to interdependencies found within healthcare supply chains and how these impact ISs used in the healthcare industry. Studying how and why different interdependent activities relate to each other suggests important reasons for greater collaboration within the healthcare supply chain. In addition to the theoretical development of logistics services as a complex system, this approach is beneficial to healthcare management practitioners. Rather than following the predominant deterministic view of logistics services that follows a planning paradigm, it provides a fundamental and alternative understanding of managing healthcare services as emergent logistical process. This implies a focus on resource transformation and use as local and emergent dependent on its more slowly changing organizational context. In practice, this implies providing basic conceptual models on reorganising healthcare services through facilitating and using flexible resources. This is a starting point for developing healthcare operations.

Regarding technical particularities, Kritchanchai [7] points to the importance of data standardization, pooling data in centralized locations, track and traceability functionalities, and standard data exchanges as fundamental in the development of healthcare services. Furthermore, proper healthcare involves intensive patient - doctor interactions in diagnoses and treatments. Healthcare service is a complex system consisting of a set of interactive emergent processes.

These two factors: 1) interdependency to point out particularities of networking in healthcare services; and 2) complexity pointing to uncertainties in healthcare service processes; are the two conceptual building blocks in the analytical framework of this study. Binding interdependency and complexity together provides ample direction to developing how information flow may better support the provision of healthcare services to its users. Engelseth and White [8] initially developed the conceptual framework of this work through a conceptual study. In this study we provide more detail to the cases, more through analysis and finally conceptually model the healthcare services process pointing to how healthcare services may be treated as complex systems.

The next section introduces the four important topics integrated in this paper to create an analytical frame of reference: 1) The status quo of healthcare services; 2) healthcare service particularities through focus on interdependencies; 3 ) complexity focusing on the emergence of value-producing healthcare; and 4) information use in healthcare service networks.

\subsection{Status quo}

Errors are abundant in healthcare services - often due to poor information quality. Medication errors can occur [9-12]; these authors found that transitions from one healthcare setting to another increase the risk of medication errors due to lack of communication and, consequently, information loss. These errors can cost human lives, prolong hospital stays, and may have serious financial implications for health services. To meet these challenges in offering safe and high-quality healthcare, inter-professional health systems need to undergo organizational paradigm changes [13]. People receiving home care services usually have multiple morbidities, functional impairment, cognitive impairment, and polypharmacy [14, 15] which increase the risk of cognitive impairment, falls, hip fractures, hospitalizations, adverse drug reactions, and mortality 1617,18$]$.

Palmer et al. [19] found that the implementation of new interventions, worked out together with healthcare providers and patients with mental illnesses, could be suitably arranged by the management of the institutions to better manage practicalities and logistics. Inter-professional collaboration helps streamline patient pathways and foster the flow of knowledge and good practices between the professionals and their employing organizations [20]. Effective communication is considered a key factor for successful collaboration [21]. The informants reported more efficient but less personal (and therefore less effective) communication between general physicians and nurses after the introduction of E-messaging between them [21]. This implies that face-to-face personal communication does have value in a healthcare setting. In healthcare services, there is a fundamental need to develop ethically founded patient-responsive flows of treatment. This also demands increasing managerial sensitivity to the inherent complexity of healthcare service production. 


\subsection{The structure of healthcare services}

Interdependency points out the organisational reasoning for interacting in a network structure. Healthcare services are thus viewed as emergent in their complex organizational context, a product of interaction. Pointing out interdependencies of organizational relationships among actors helps describe the structure of the network within which healthcare is carried out as an activity. At a fundamental level, following Parsons [22] view of organizations, an environmentally contingent understanding of production as embedded in organizational layers of the supply chain may be accounted for through: 1) operations; 2) management; and 3) institutions. Operations include logistical processes, the activities that produce value. This understanding implies that services are produced, managed, and evaluated by customers as well as suppliers. Institutionalized behaviours resulting from an established discourse represent the context of production. Interdependencies may, according to Thompson [6], be either pooled, sequential, or reciprocal. Following Thompson [6], the structure of an industry network (its "supply chain") may be characterized by describing the importance of these interdependencies in relation to each other. In services, either pooled or reciprocal interdependencies are dominant. This understanding was elaborated from a strategic perspective by Stabell and Fjeldstad [23] who conceptually modelled how services may be developed either as a value network (pooled interdependencies dominant) or as a value shop (reciprocal interdependencies dominant).

Furthermore, according to Pfeffer and Salancik [24] and Leonardi [25], interdependencies can be managed, increased, or reduced; or the dominant interdependency in a dyadic relationship can be changed. This implies that, over a long term, the context of services production may be modified by focusing on changing interdependencies. For instance, reciprocal interdependency may be reduced in services by increasingly standardizing resources such as information, knowledge, goods, facilities and tools. This may strengthen the foundation for increasing pooled interdependence in the supply chain. Pooled interdependency provides opportunities for limiting the role of the more manual mutual adjustments in business relationships. This increases the automation in providing supply chain services. This would have consequences regarding the role of people since human sensemaking is more limited with pooled interdependencies.

In their generic form, services are commonly classified as intangible, heterogenic, inseparable, and perishable. However, this static classification provides, according to Spring and Araujo [26], limited analytical value mainly because it does not consider the importance of the typically emergent processes network interactions of which services production consists. This implies that service production demands a different mode of organizing [27, 28].
In services, human "sensemaking" [29], which produces logistical decisions, is often still a manual task. Therefore, people emerge as a key factor in service production. The people resource and human interaction are, therefore, fundamental to achieving an acceptable quality of service that provides an organization with a competitive advantage in the marketplace [30, 31].

Sampson and Froehle [32] also underpin the importance of people when they state, in their effort to conceptualize service processes, that "...with service processes, the customer provides significant inputs into the production process." Service production cannot start before the customer provides the supplier with input. This implies reciprocal interdependency between the supplier and the customer. According to Sampson and Froehle [32], three types of customer inputs can be found in services: 1) customer identity; 2) physical resources, such as customer belongings, tools, and other tangible objects; and 3) pertinent information. These inputs are pooled and, in combination, produce a service. Another distinct feature of supply service is that some supply chains can be characterized having a "hub and spoke" (as well as a feedforward) like structure. Furthermore, service industry supply chains are, according to Sampson and Froehle [32], short, as well, since more than three tiers (a triadic form of collaboration) of organizations is rarely found in a service supply chain.

Regarding operations of service provision, Sampson and Froehle [32] cite empirical evidence of quality issues predominantly found in supply chains to include random arrivals, inconsistent specification, and varying input quality that influence service capacity, demand management, and quality management. Bicheno and Holweg [33] discuss typical forms of waste (in lean thinking this is often labelled using the Japanese word muda) found in services seeking to become lean which are represented by: 1) delay; 2) duplication; 3) unnecessary movement; 4) unclear communication; 5) incorrect inventory; 6) poor customer service; and 7) transaction and production errors.

Following Stabell and Fjeldstad [23], building on Thompson's [6] contingency theory, services with predominant reciprocal interdependency involves costly manual exchanges. Reducing the costs of service processes involves minimizing the need for intensive interaction typical of reciprocally interdependent relationships. As already noted, interdependencies can be managed, including changing the fundamental nature of a relationship context for interaction. In healthcare services, there are various points of interaction between patients and healthcare service suppliers, and resource capacity is a cornerstone in providing timely services. This involves pooling various resource-types such as people, tools, and goods. Following Bicheno and Holweg [33], an efficient and effective lean service is supported by a set of pooled heterogeneous and complementary resource 
tools such as reservation systems, price incentives, promotion of off-peak demand, and customer self-service.

\subsection{The complex processes found in the logistics of healthcare services}

Healthcare as an environmentally contingent service is always to some degree complex. This section sheds light on the concept of complexity as the foundation to further understand healthcare services and its use of information technology (IT) in such industrial settings. Complexity is associated with uncertainty, as evident through observing process emergence. Logistics is in the case of services concerned with transformation as changes in resource pooling. This pooling is a planning problem associated with creating for the actor a context of flexible resources paired with knowledge on how to use these resources efficiently. In line with Lichtenstein's [36] view of generative emergence, this implies the intentional and complex creation of organizations. It includes agency as a part of the emergence concept and consists of two drivers: 1) intent to create value; and 2) methods for doing so [33]. In this space of interaction in the supply chain, human perception is in perpetual change, (i.e., fluid). "Space and time are phenomenal, that is, they are intra-actively configured and reconfigured in an ongoing materialization of phenomena" [34]. Organizing information means focusing on agency in complex systems to seek value as the overarching purpose within the system, and describing the tools used by the agents to reach these goals. Agency is the capacity of individuals to act independently and to make their own free choices in context [35]. In healthcare services agency represents predominately managerial action of the networked human knowledge resource. Agency is relational, to other networked agents in a healthcare system. Networked agents represent the supply structure, a context for producing healthcare services manifest as emergent processes. Such service provision, returning to Parsons [22] view, is the institutionalized behaviour that is the most evident element of this context. Professional culture embeds learned healthcare service activities, a discourse. In services agency is increasingly important since production and exchange are in the same flow as different aspects of the healthcare service. According to Lichtenstein [36] agency simply implies agents in action or agents who possess " $\ldots$ a self-conscious motivation to cause order to arise." These agents are the actors who must learn how to use as a continuous pooling facilitated by observation in the near context and supported by an information system facilitating this search for immediate process direction.

Agents in networked interactions represent the root of organizational complexity [37]. According to Lichtenstein [36] agency provides the grounds for exploring how emergence may also involve the creation of organizations. Our research approach regards this system complexity as being well matched to the problem of creating viable ISs. ISs may contain multiple resources supporting different forms of agency limiting human intervention, and these elements can be interconnected within defined system boundaries to define a common functionality. A core functionality of an IS, either with predominately pooled interdependency or reciprocal interdependency, is to effectively interconnect the agents. Since IT is relatively cheap currently, the prime concern may seem to be more the IS's effectiveness than its efficiency, however not forgetting the importance of patient (customer) value, an effectiveness measure.

Complexity can be defined, according to Rzevski and Skobelev [38] as: “... a property of an open system that consists of a large number of diverse, partially-anonymous, richly-interconnected components, often called agents, has no centralized control and whose behaviour emerges from the intricate interaction of agents and is therefore uncertain without being random." Rzevski and Skobelev [38] also point out that the key features of complexity are openness, diversity, partial autonomy and interconnectedness of agents; lack of centralized control, and emergence. This component interlinking fosters interdependence. System complexity is not necessarily a random chaotic "thing" out there. The behaviours of complex systems, most effectively operating at the "edge of chaos" are not "random" and do not arise purely by chance. A complex system implies production process emergence and services produced evolve, taking this approach, based on interactions within its boundary and interactions with its environment across its boundary.

A complex system can be influenced by design, or, more likely, thoughtful interventions that may, with sufficient time, lead to improved behaviours; one must consider taking a different approach and try to intervene again. Typically, these responses are exhibited by patterns that may be observed but are often difficult to interpret. Simple, direct responses often cannot be reliably correlated with particular interactions or interventions. So, although there is cause for hope, the challenges are great. However, much can be learned about the patterns of a complex system by applying the tools of agent-based modelling and simulation in a virtual imitation of the complex system that operates in parallel with the original - perhaps in an accelerated period [39].

In services, exchange is highlighted $[6,23]$ because production often takes place as interwoven production and exchange flows since the people producing the service are also the ones negotiating with the customer how to design and carry it out. It is a process where consumption and production may be more or less simultaneous. This is the case in the healthcare industry where highly competent practitioners and/or leaders such as doctors and nurses both manage and produce. In healthcare services, managers may therefore have dual roles that include producing the service, not 
only managing it. As discussed, exchange may often involve - in cases of reciprocally interdependent relationships commonplace in patient treatment such as sickness diagnostics - demanding mutual adjustments through inter-professional and inter-personal communication.

\subsection{Information use in healthcare service network}

IT represents the scope of IS potential. In supply chains Information technology (IT) represents a generic technology resource; a potential use for all participating agents. When taking a supply chain management (SCM) perspective, IT's resource base importantly includes integrated information hardware and software design, development, and use. Three aspects of IS potential are commonplace in current research on "cutting-edge" IT use in industry. This includes features of connectivity focused on the Internet of Things (IoT) expanded to include connectivity associated with people and documents [41,40]. Second, features of what is commonly considered as big data (BD) [41] are commonly discussed. This directs attention to complex or large amounts of data challenging the design of data-processing application software. Such data is characterized by: 1 ) volume (quantity of generated and stored data);2) variety (type and nature of the data); 3) speed (rate at which the data is generated and processed); 4) variability (inconsistency of the data); and 5) veracity (quality of captured data) [42]. These features add up to, arguably, data complexity rendering BD by itself as an inadequate formulation to describe features of this technology-driven change in data capture, processing, and use. Data is not information, but the foundation of creating data comprehensible by people - which we call information. Third, IT may be applied to integrate various resources in multi-tier service supply chains. This includes applications supporting track and trace functionality adapted to support service provision which create the grounds for producing customer value in a multi-tier, complete supply chain [43]. IT is central in this endeavour. However, the institutional barriers to achieving this goal are hampered by incompatible interconnection abilities due to the disparity and diversity of most of the ISs in place [44]. This seems to be a fertile area for standards development among hospitals and other care giving organizations. Also, the public needs to be disabused of their likely penchant for privacy in withholding any of their personal and health information which tends to prevent sharing of trend-able data that might greatly help improve the general health of the public.

Safeguarding caregivers from routine mistakes in treatment is another critical area for improvement. Here, it is advisable to have some redundancy in staff and procedural overlap in checking details as patients are treated. Instead of recording specific regimens manually with pen and paper, IT should be able to realize this checklist process in a simple, less time-consuming, and more accountable way. ISs of this sort should be designed to be so user-friendly that doctors and nursing staff can be relieved of most of the time-wasting data-entry and retrieval tasks in order to concentrate more on interacting with patients on a personal level. This implies great care in preparing the IT applications in consultation with practitioners who can guide the development toward more useful capabilities.

One of the prime features of a healthcare network structure is that agents must interact in order to produce this kind of service and, thereby, secure value for the customer. ISs support this need by providing and messaging information to help agents integrate. The level of integration in a supply chain is important in describing how an IS interconnects its users, both within and among firms (internal and external integration). This information connectivity is a form of supply chain functionality that supports integrating not merely the things advocated by IoT, but also relevant documentation (information artefacts used to message and store information both in paper and electronic form), and people (who possess both labour and knowledge resources). Especially in services, where pooled interdependency necessarily is important [22], it is more than moveable artefact-type resources such as tools or goods that need to be pooled. In addition, information and people need to be combined in a seamless manner to create the service.

In the artificial intelligence field, researchers and developers are investing large sums and working very hard to create robots that mimic human behaviour, and it is clear that robots are taking over more and more jobs that displace many workers [45]; this is one automation-related outcome of IoT. One of the ironic qualities of standards is that there are so many of them; standards efforts often result in more complication which tends to divide people rather than bring them together. Along with the rise of social media, younger people seem to care less about privacy, and many of us are shopping more and more online, not caring much about how our habits and preferences are adding to the information available to profiteers for exploitation. Security is also hampered by trying to protect too much rather than realizing the benefits of information sharing and being mindful of only what really needs to be protected. Theoretically, at least, information in its electronic form can be easily and inexpensively stored, processed, retrieved and transmitted using IT resources. An important change in recent management thinking is associated with applying the concept of BD. However, we are critical of this term since it cloaks (for analytical purposes) the true nature of electronic information embedded in a supply chain. Certainly, BD has analytical potential at a general management level; but in the specialized management context of a service supply chain, it is not the nature of data as being diverse, changing, speedy, 
inconsistent, and of varying quality that is a management challenge; this would essentially demand BD analytics to solve this problem. On the contrary, these features, as characteristics of IT enabling IS development, represent a vast potential when considered from a SCM perspective. This realization needs to be integrated into existing and future SCM software rather than merely representing particular IT resources being used automatically from an organizational side-line. This is predominantly because in SCM it is not the hidden data (which is of essential value to agents that needs to be mined) but real-time data related to production flow. These data are embedded in a technological context paired with fluctuating customer value perceptions. In healthcare logistics, the essentials of this mixed exchange and production flow must be properly visualized and managed to better effect desirable outcomes.

The key stakeholders, doctors, nurses, technicians, administrators, patients, pharmaceutical drug suppliers, insurers, etc., associated with healthcare production flow must meet regularly and communicate what works and what doesn't within and at the interfaces of their respective domains. This is a necessary but insufficient process for improving healthcare logistics. As specific problems and potential solutions are identified to elucidate a vision, specific goals, and desirable outcome spaces, stakeholders should consult state-of-the-art technologists to suggest attractive (helpful and affordable) IT-based enablers that might be applied. Then limited experimentation using such IT augmentations should be conducted as safely as possible to see how well they work over a reasonable period of time. To the degree these initiatives are successful; they will be adopted more widely. If further problems arise as a result of this experimentation, then different interventions need to be considered and applied. All of this critically depends on the abilities of everyone to share information, build trust, and strive for open mindsights, keeping the health and well-being of patients as the ultimate goal. IS development takes place in an inter-organizational entity we term "the healthcare service chain." As an organizational structure this approach founded on SCM directs attention to a normative quest where integration supporting collaboration between supply chain agents is believed to be the prime route towards improving the quality of the healthcare services. This vision is founded on enhancing through considering networked interdependencies the particularities of healthcare services as already discussed. Furthermore, this approach needs, as discussed in the preceding section, integrate a fundamental view, that collaborating to produce this service should be understood as a complex system. This means that from a strategic perspective ISs in healthcare services must be designed to facilitate interaction in processes more than detailed planning of the process.

\section{Methods}

The provided case narratives exemplify current practice in healthcare services. The first subcase provides a narrative of commodity flow at a Thai hospital. The second subcase concerns the treatment flow of a psychiatric patient focusing on consequences of unexpected and poorly informed changes of the flow. The third subcase addresses the standardized organization of information flow related to moving patients between hospitals and home care facilities in Norway. Together, these subcases provide different windows into issues regarding integration and information connectivity in healthcare service supply chains. Each subcase is individually analysed based on the literature review provided in Sect. 2. These cases, were as described in the introduction, presented in brief as examples in a preceding published conceptual study of complexity in health care services [8]. Here these cases are described in further detail to support conceptual modelling.

The first subcase, to be described in Subsection 4.1, took place in one of the state-owned hospitals in Thailand. To understand the logistics flow of medical commodities in the hospital, one type of frequently-used medicine was selected and studied, in depth, within its supply chain. Information gathering included five face-to-face semistructured interviews conducted with the procurement manager, the warehouse manager, pharmacists in the outpatient department (OPD) and inpatient department (IPD), and the hospital's supplier. Interview questions were aimed at investigating the flow business processes, including the medicine's operational flows across each function, inventory management, and the IT applied. Resulting narratives were recorded, and the key issues were highlighted. Then, a focus group consisting of the same target group from the hospital and a representative from the supplier was formed. They drafted a business processes model and offered that to the participants for verification. Subsequently, several problems were raised and an overall consensus was reached.

The second subcase, to be described in Subsection 4.3, involved an authentic incident that occurred in an outpatient psychiatric clinic in a Norwegian Hospital Trust; it represented customary priority setting procedures. One of this paper's co-authors is directly involved in these practices, including their development. The associated narrative is a brief account of this researcher's contributions.

Patients are granted the right to medical assistance in two categories: 1) the right to consultation, perhaps including examination or testing; and 2) the right to further medical treatment. Having these two categories relieves pressure on the patient waiting list by separating the consultation and medical treatment allocations. Thus, 
the hospital can offer patients a single consultation with ensuing options of either denying treatment by a specialist directly providing treatment via medications, physical or psychiatric therapy, advice, and so forth, or (thirdly) by transferring the patient to a general practitioner (GP) for treatment. These first two options facilitate improved scheduling that may benefit other patients. Unfortunately, the third option may lead to breaches of any established treatment closing deadlines, thereby complicating the administrative system operated from the Norway Hospital Trust overseen by supervisory authorities.

Ahead of a patient being granted the right to medical assistance, the clinicians make ongoing assessments of the patient's need for examination, treatment, and followup [46]. In general, the considerations of severity, benefit, and resource-use are relevant for assessing prioritization throughout a clinical pathway, which is particularly important to be aware of if the right to medical assistance has been granted in the form of examination and/or testing. Interspersed with this are the clinicians' subjective assessments, based on their own medical discretion, and unforeseen events within the hospital. The priority setting guidelines give clinicians, who consider the referrals, directions to measure waiting time, from receiving the referral until starting consultation or treatment. These waiting times are recorded in the patient administrative system, and waiting list statistics and related information is generated. Waiting time statistics can be used by health authorities in benchmarking acceptable wait times or comparing waiting times or wait lists among hospitals. However, the numbers shown in these statistics do not highlight or distinguish recording errors or internal defaults.

The third subcase presented in Subsection 4.5 took place when general practitioners (GPs) and nurses in a home care system in a Norwegian municipality described how they communicate with the staff at a state-owned hospital. First, a face-to-face focus group interview was conducted with a group of four GPs in a municipality-driven office taking care of patients living at home. The GPs were asked about how they communicate with the staff at the state-owned hospital and the nurses in the home care system about the patients being moved between the hospital and homes. A group of five nurses in the home care system was also interviewed about their experiences related to cooperating and communicating with physicians at the hospital and the GPs when patients need help. The narratives were recorded and the key issues were highlighted. The findings were drafted and given to the participants for verification.

More generally, we remark that case studies provide a means for highlighting and extracting practical principles and methods for shaping and accelerating progress in solving pressing real world problems. Case studies inform burgeoning theories such as those associated with complex systems engineering where people are considered part of the system to be conceived, developed, fielded, and operated; or extant systems targeted for improvement upgrades [47]. This paper advocates for the importance and value of case studies in advancing improvements in healthcare supply chains and their management. In particular, a case study template (somewhat abbreviated) that can be used as a guideline in reporting on case studies of complex healthcare systems is found in a work in [47].

\section{Results}

Three problematic subcases are presented in this section: 1) the logistical flow of hospital commodities; 2) waiting lists; and 3) effective communication in emergency situations. In reading these subcases and the issues they raise, consider how they could be expanded into full-fledged case studies. The subcases are following its description analysed individually and then conceptually modelled following complex systems thinking. The sub-analyses point to features of organisational structure, the healthcare process, and IT use.

\subsection{Subcase 1: The logistical flow of commodities at a hospital}

The study took place in one of the state-owned hospitals in Thailand. To understand the logistical flow of medical commodities in the hospital, interviews were conducted and focus groups were employed. Hospital commodities were physical artefacts, logistical goods that were typically applied in services at such institutions. The questions were aimed at investigating how medical commodities flow and were managed. The study found that all medicines and their active ingredients were managed by pharmaceutical groups. There were three major medical functional areas in the hospital: 1) the storerooms, 2) the central warehouse, and 3 ) the procurement department. Four medicine storerooms were located in the OPD, and one medicine storeroom was located in the IPD.

The hospital had two principal ISs for inventory management: one in a back office and the other in a front office. The back-office IS was used for managing inventory at the central warehouse. As the warehouse pharmacists received medicines, data associated with these were recorded in the back-office IS section.

The front-office IS was used to manage financial and inventory data at the front office and the storerooms. Although both ISs were employed for different purposes, they were synchronized once a day at midnight in order to transfer information between them. Figure 1 depicts this medical supply chain. 
Fig. 1 Medical supply chain

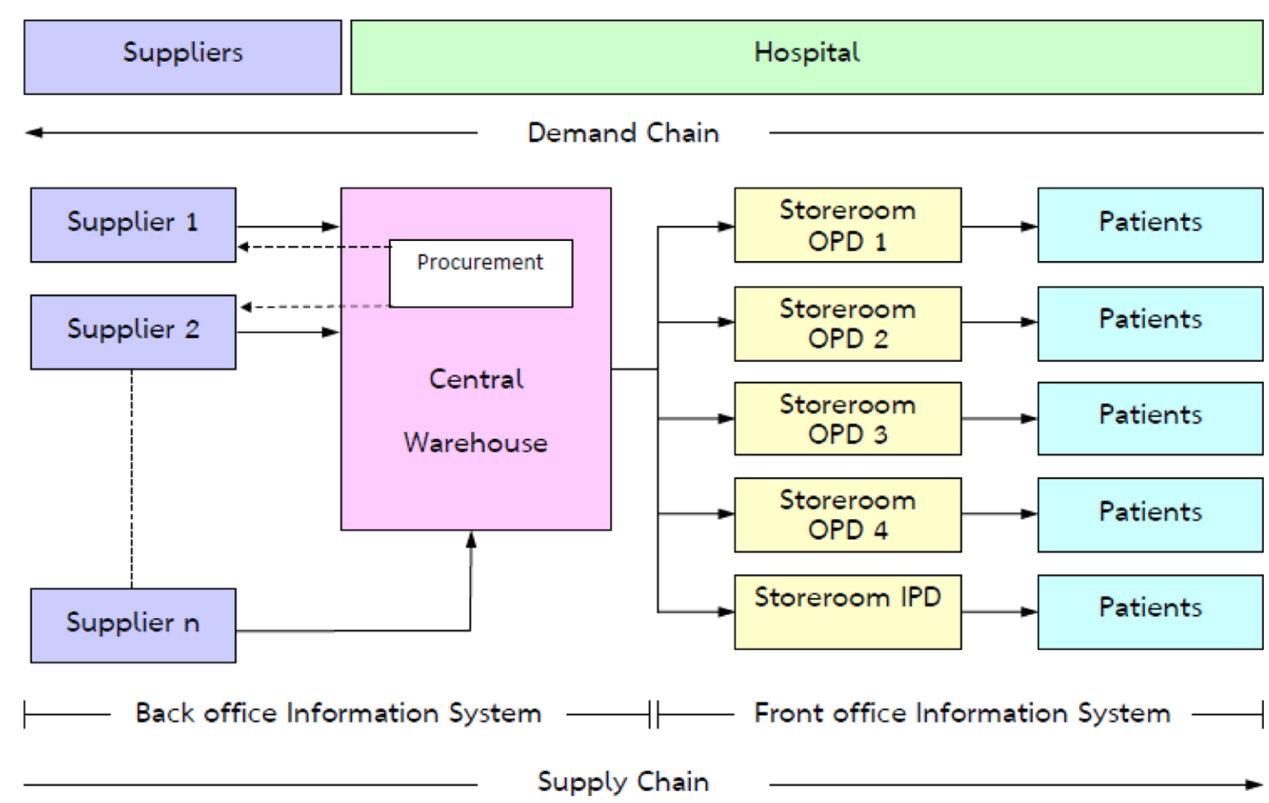

Currently, the procurement department deals directly with various suppliers from both public and private sectors. The procurement process is accomplished after both purchasing requisition (PR) and purchasing order (PO) documents are approved. PR takes approximately three to four weeks; this varies depending on the volume and intricacies of procurement activities. A PO requires three more days. PR and PO documents are accomplished [fulfilled] manually. The only information technologies used are E-mail, facsimile (fax), or telephone. The hospital staff needed to spend a considerable amount of time on this process, and human errors inevitably occurred.

For instance, one important type of hospital commodity - medicines sent by suppliers - are delivered to the central warehouse. The warehouse pharmacists are responsible for manually checking the deliveries against the POs and storing these medicines in the warehouse. All the relevant information (e.g., data involving the amount of medicine, the supplier, batch number, etc.), is recorded in the backoffice IS at the warehouse. Then the warehouse distributes medicines to each ward (OPD or IPD) storeroom according to their existing PR requests. The medicine requisitions (PRs) from each ward to the central warehouse are prepared by each storeroom's pharmacist. Based on their experience, each pharmacist estimates the quantity of each medicine to replenish the stock in each ward. This depends upon the level of stock left in each storeroom and other conditions such as seasonal diseases, emergency requests, new government regulations, etc. Each storeroom pharmacist executes their demand order (PR) manually via a request slip to the central warehouse every day at 9 a.m. The warehouse collects all these requests and supplies the appropriate like amounts to each ward later in the day. In the storeroom, all the relevant product information, (e.g., transaction data involving usage level, inventory level, etc.) is recorded in the front-office IS area.

\subsection{Subcase 1 analysis}

Managing goods flows is a core feature of logistics. Here, the flow of goods supports the core healthcare service provision. This is a physical flow of goods. One of the key aspects of this flow is the overstocking problem as described in the narrative below. This was a classical logistical problem reminiscent of the "beer game" created by Jay Forrester [48] and further publicized by Peter Senge [49]. One factor that contributes to the exacerbation of the problem is the natural and persistent time delays that may occur between steps in the overall logistical supply chain process. Possible mitigations to this phenomenon would be to endeavour to apply IT more effectively to not only reduce the manual labour of the participants but also to speed up the process, thereby reducing the human errors as well as the time delays. A probable solution, following Lee et al. [50] and Lee [51], is to further supply chain integration on various functions such as ordering policies, forecasting, information sharing, etc., facilitated by a more seamless information flow.

This subcase's narrative seems to show that the frontoffice and back-office ISs are integrated and that the information flows smoothly. In practice, however, the IT applied here did not satisfy quality requirements regarding place, time, and form. For instance, the storeroom pharmacists admitted that the actual physical stocks and their representations in the IS might differ. When the recorded amounts are transferred to the back-office IS, that system calculates and suggests the replenishment levels to the storeroom. Since 
the volume of goods in the system is not accurate, the backoffice administrators often increase the suggested replenishment levels based on their own experiences with overstock allowances. This tends to cause overstocking in the storerooms. Moreover, when the central warehouse supplies these overstock levels to the storerooms; they consequently also request higher replenishment levels from suppliers. This results in the internal supply chain's exceedingly high inventory levels.

Noticeably, the role of IT here could have helped facilitate quality information sharing but this would still not have been sufficient since the medicines inventory management system was continuously manually overruled by the administrators. This implies that IT is a necessary but not sufficient source of process improvement in healthcare services. Such ITenabled development must be coupled with organizational change. Interconnectivity is still a fundamental requirement for this organizational change to happen.

This process is summarized by the qualitative model of Fig. 2 following the "systemigram" style depiction advocated by Boardman and Sauser [52]. Unfortunately, one link from the Storeroom Overstocking "bubble" crosses two other links. One goal in preparing these systemigrams, sometimes difficult to satisfy, is to keep this type graph planar with no crossing links.

\subsection{Subcase 2: The waiting list paradox}

The waiting list is typical of healthcare service allocation in many economies. This creates a need to carry out tradeoffs that may be related to time in queues compared with criticality of healthcare treatment for the patient. Trade-offs involve societal points of view. The general public inevitably set limits to healthcare because publicly-financed healthcare services compete with other forms. Thus, healthcare needs are met under conditions of not only government regulations but also market competition; thus, implying significant resource constraints. Clinical care service flows involve prioritization rules that are based on a combination of partially contradictory factors including expected benefits of healthcare, cost effectiveness, and individual circumstances. A patient treatment flow is shown in Fig. 3.

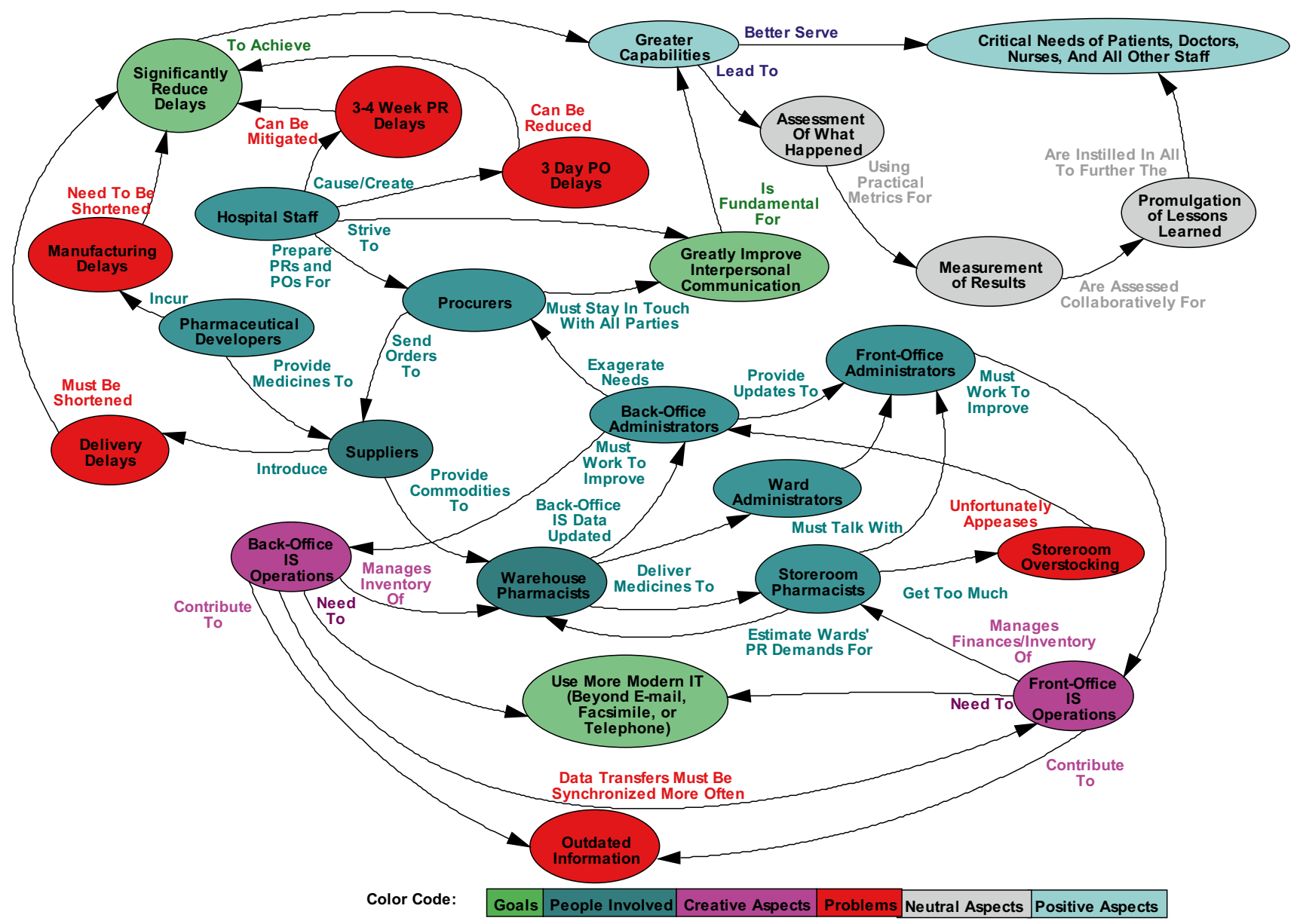

Fig. 2 Logistical Flow of Hospital Commodities 
Fig. 3 Patient treatment flow

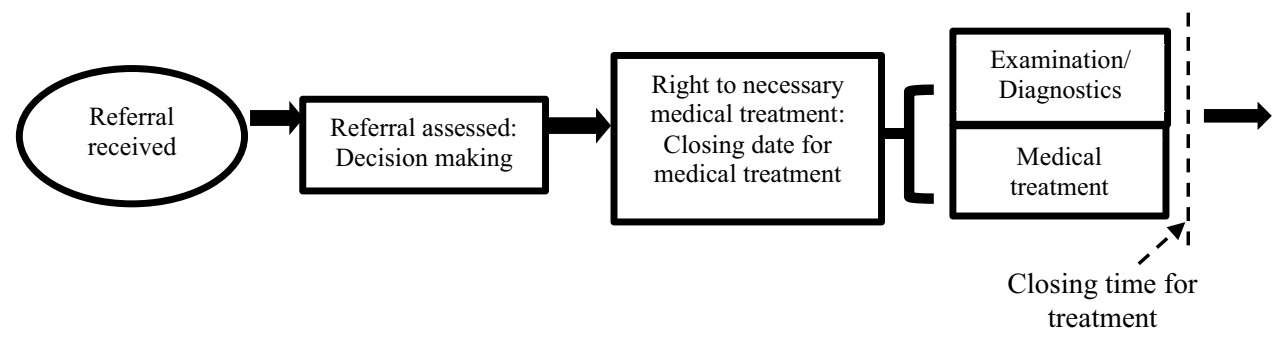

Figure 3 depicts a healthcare service process in general terms and does not reveal emergent characteristics of such a flow. It can be considered a general guideline for patient treatment as discussed in the following example. This narrative starts with a GP referring his 40 -year old patient to a psychiatric outpatient clinic, a specialized healthcare service. The patient exhibited moderate to severe symptoms of depression, and the GP expressed uncertainty about diagnosing the patient's condition. On the referral form, the GP underlined the level of urgency of the healthcare considered necessary, and asked for an assessment of the medical condition within a week. A multi-disciplinary team of specialists, who considered the referral, was to decide whether the patient should be granted the right to necessary medical examination and subsequent assistance, or whether the referral was to be rejected. Based on principles of priority setting criteria for psychiatric disorders, together with available clinical guidelines regarding depression, and the patient characteristics, nature and severity of symptoms described in the referral, the multidisciplinary team did not identify any suicidal tendencies, and decided to offer the patient the right to examination and an appointment with a psychiatrist within four weeks. The team transferred the patient to a psychiatrist, who met him for a single consultation within the four-week deadline. Thus, the priority setting criteria for medical treatment and examination services to be rendered within a justifiable time limit was met. Upon referral, the patient was taken off the official medical waiting list. Instead, the patient was placed on an internal personal waiting list of the specialist institution.

However, when the psychiatrist first considered the patient to be suffering severe depression and wanted to prepare a treatment program for him, the psychiatrist also became ill and had to cancel the next consultation. Pending the recovery of the psychiatrist, the patient did not get a new appointment or a new therapist. The patient administrative system formally recorded this (partial) healthcare service as being fulfilled within a prescribed time limit, because he had the first consultation; but the system did not detect that the patient was no longer included in the outpatient clinic's patient portfolio. After nine months, as the psychiatrist was still on long-term sick leave, the patient's wife called the outpatient clinic and requested a new appointment for her husband who was still on sick-leave and influenced by severe depression symptoms. This illustrates an apparent paradox: A patient was recorded as finishing treatment in the general waiting list, despite still being ill, because the status of the patient recorded in a local waiting list was not taken into consideration as data in the general waiting list.

\subsection{Subcase 2 analysis}

From this narrative, we can conclude that there is a need to plan for unforeseen contingencies in healthcare supply chains. In this subcase, the psychiatrist who was designated to treat the patient fell ill. Leaders and managers must recognize that the unexpected will inevitably occur in complex environments, and that a process for addressing such events needs to be defined in advance with as much appropriate detail as possible. Although it is impossible to predict precisely the circumstances of such events in healthcare management, there needs to remain an awareness concerning a certain degree of uncertainty in events that may particularly surprise the actors. In such scenarios, having a process already in place that is automatically triggered will at least have the benefits of saving some time and unnecessary consternation.

One of the key problems depicted is organizational. There were two ISs used in this subcase: one general, and one local. Since they are connected to each other (where the output from the general system is playing the role as input to the local system), this cloaks transparency. What goes on in the psychiatrist treatment session is hidden from the general system which disables control from a larger perspective. In this subcase, it was the patient's wife who needed to solve this information discrepancy.

The scope of possibilities for discrepancies needs to be expanded to include an examination of the implicit assumptions that ignore the possibility that a caregiver might be taken out of service. As in all good engineering practices, one must consider what might go wrong in a well-intentioned process. In fact, stakeholders should sometimes devote more attention to this aspect rather than to optimistically expect satisfactory results from established plans or recent interventions. Therefore, healthcare services need to secure transparency through interconnection and 
informational subsystems; and these subsystems also need to handle uncertainty through use of flexible information resources that create sufficient transparency to reveal discrepancies or changes in the healthcare supply chain. A conceptual model of this process is provided in Fig. 4. Again, there is one non-planar link.

\subsection{Subcase 3: The emergency flow and inter-professional communication about patients moving between hospital and home care}

When people in Norway get critically ill, they or their representatives could call the emergency number 113 and get help from skilled staff working in an ambulance. These emergency medical technicians typically would bring the patient to a hospital where physicians and nurses will assess what treatment is recommended and applied, and how long the patient needs to stay. See Fig. 5.

If people get sick at home without needing an ambulance but still feeling symptoms resembling an emergency, the preassigned physician is called first. Typically, then the patient visits the physician at his/her office to discern whether to be hospitalized. See Fig. 6.

If hospitalization is required, the hospital staff diagnoses the patient and considers when to move the patient back home. In some situations, the patient may be provided home care delivery or sent to a nursing home when there is a nonlife-threatening ailment. However, the home care system is not prepared to take care of patients with much more serious diseases. Nevertheless, some home care patients later become critically ill.

The hospital and general physicians and the home care nurses usually communicate by electronic messaging. Yet, these messages and even phone calls, often used for

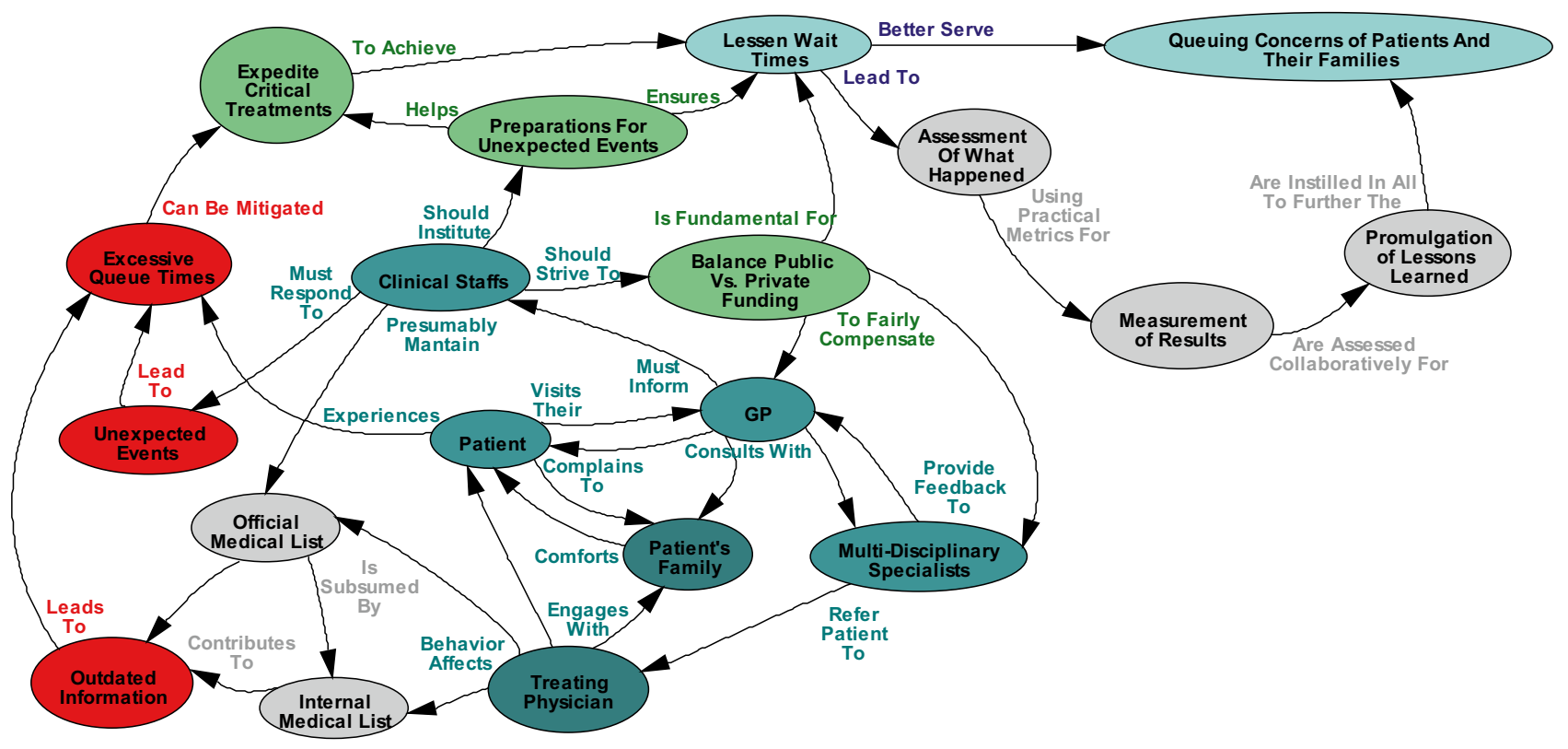

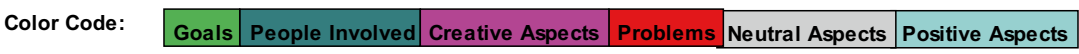

Fig. 4 The Waiting List Paradox

Fig. 5 The critical need patient emergency flow

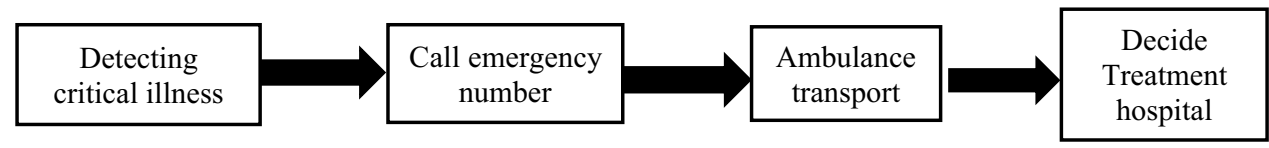

Fig. 6 The less critical emergency help flow

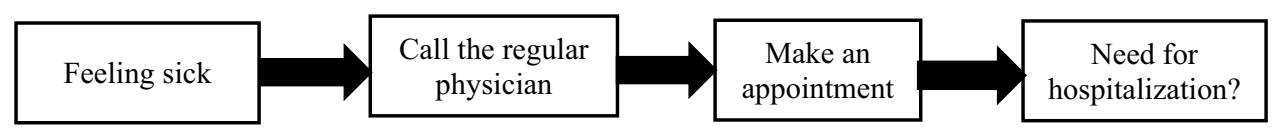


clarification, do not accurately impart and capture all the relevant information and knowledge required. In addition, nurses feel an increased risk of misunderstanding without any inter-professional and inter-personal contact or meetings. Therefore, both nurses and physicians advocate for the importance of working together in person which naturally leads to further clarifications as well as new information and knowledge.

The physicians also express their need for inter-professional information exchange to manage taking care of all the critically ill patients in the home care system - especially those who never visit them. Both the nurses and the physicians feel a responsibility for enhancing routines, and for following up with all the critically ill patients living at home.

\subsection{Subcase 3 analysis}

There is a dearth in the number of favourable ways to clarify responsibilities among the different professions involved. Communication is often pointed out as the most important factor for inter-professional cooperation - both by the nurses, and, even more, by the general physicians or GPs. However, electronic communication cannot substitute for the positive effects of meeting each other face-to-face to experience the often subtle but invaluable cues. This third narrative shows the importance of integration in the supply chain to support the healthcare service flow. It can be described following a timeline, meaning decisions are sequentially interdependent. In the two scenarios illustrated in Fig. 5 and Fig. 6, an initial decision renders what type of flow is followed based on a first-step evaluation of degree of criticality. In both scenarios, time is critical, but in varying degrees. Patients sent directly to hospitalization are clearly more time-critical. Furthermore, cogent decisions imply resource pooling, primarily with information resources integrated with communication resources. To properly administer patient flows, the appropriate agents must be informed of the recommended treatments.

Accordingly, the role of agency is a core feature and concern in analysing healthcare flows. Clearly, such flows are impaired by uncertainty, and the natural thing to do is to determine treatments through relationships characterized as reciprocally interdependent. This interdependency, is however, clearly toned down since time is the main critical factor in healthcare emergencies. Intense interaction takes time, and, therefore, reciprocal interdependency in emergencies is likely inferior to predominately pooled interdependent service production. Pooled interdependency is amenable to increasing the automation of the healthcare service flow since this involves standardizing the activities such as diagnosis, sensemaking, treatment, and information sharing.

This process is qualitatively modelled in Fig. 7, this time with two non-planar links.
These systemigrams attempt to capture the verbal essence of the three subcase processes discussed above but the diagrams certainly could be improved upon with additional effort. The color-coding is intended to be a clarifying feature. More importantly, these graphs purport to suggest the current process shortcomings and what might be done to improve these situations. Again, further case studies, particularly those that test the veracity of these systemigrams, are encouraged. The authors will be very interested in any results that are obtained along these lines.

\section{Discussion}

All three micro-level models of the preceding section involve inter-personal communications which is usually most effective, if practicable, if conducted face-to-face. The Enneagram discussed below can greatly facilitate that practice. In addition, we also provide a more general systemigram model that attempts to conceptually and qualitatively model the whole healthcare supply chain.

Medication management is one of the key aspects of patient safety in healthcare systems, and medication safety still continues to be a major challenge $[4,15]$. The fundamental suggestion here is to endeavour to apply the socalled Enneagram [53] to facilitate comprehensive interprofessional communication that does not leave anything out (even the "elephant in the room"). This process, which has been tried successfully in many venues, is depicted in Fig. 8 [53]. A bulleted list which at least partially explains this figure follows.

- Point 0 (Identity): Who are we? What is our identity? What is our history, individually and collectively?

- Point 1 (Intention): What are we trying to do? What are our intentions? What is the future potential?

- Point 2 (Issues): What are the problems and issues facing us? What are our dilemmas, paradoxes and questions?

- Point 3 (Relationships): What are our relationships like? How are we connected to others we need in the system? What is the quality of these connections? Are there too many or too few of them?

- Point 4 (Principles and Standards): What are our principles and standards of behaviour? What are our groundrules, really? What are the un-discussable behaviours that go on, over and over?

- Point 5 (Work): What is our work? On what are we physically working?

- Point 6 (Information): Do we know what's going on? How do we create and handle Information?

- Point 7 (Learning): Are we learning anything? What are our learning processes? What is the future potential? 


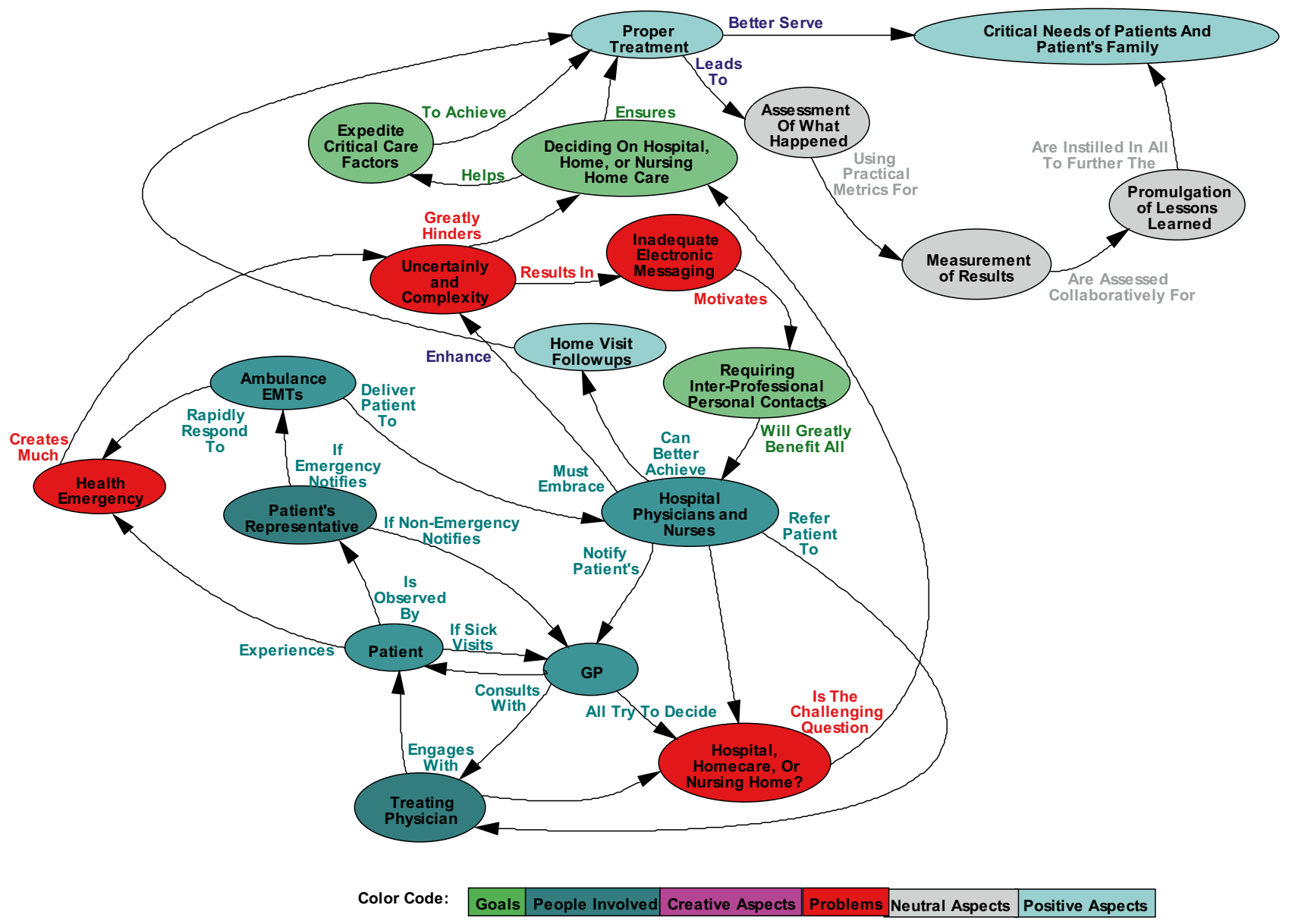

Fig. 7 Hospital vs. homecare emergencies

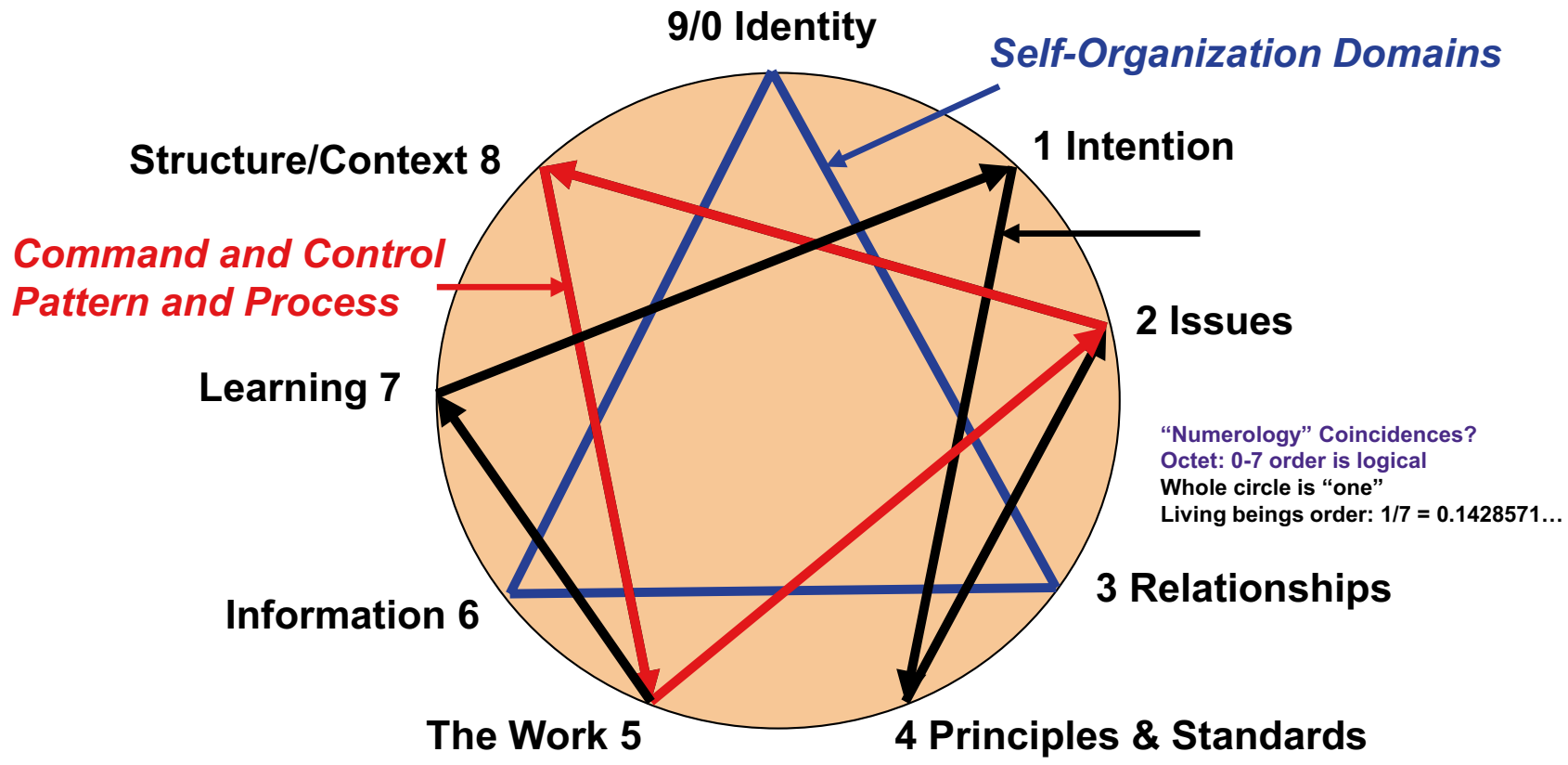

Fig. 8 Nurturing discussions, the enneagram web 
- Point 8 (Structure and Context): How are we organized? What is our structure? Where does the energy come from that makes things happen in our organization? Is our hierarchy deep or flat? What's happening in the larger environment, in which we're living and trying to thrive? Who are our competitors and what are they doing? What is the context or surrounding environment in which we are living and working?

- Point 9 (Our New Identity): After we've moved through these questions, how has our identity changed? Have we expanded and grown? What new things do we now know? What new skills do we now have? [54]. Note: Above text has been changed to read as "us," not "them."

In trying out this Enneagram discussion tool, the recommendation is to cover the points in the order $1,4,2,8,5,7$, and repeat, as necessary. We think you will find this process really works well.

Much of the above material might be summarized by Fig. 9 in a simplified qualitative modelling attempt, drawing mightily upon the work of White [55], to depict the logistical supply chain problem and some initial solutions to improve the overall situation.

In healthcare logistics viewed as a complex system, management must consider how to handle processes where components are continually in flux regarding not only the more easily measurable time, place, and form features, but also how they are interconnected (pooled), and how they are perceived. Healthcare services, as logistics in a supply chain system, emerges through analysis as complex production. Although the narratives display ample room for improvement, the status quo is hardly stable. It has undergone improvements, although this is not explicit in the narratives. Healthcare services as structure follows a timeline of change in two dimensions: 1) the service provision itself is an expression of logistical transformation; and 2) the structure of the logistical service production is the main arena for development. IS development should be sensitive to these two dimensions of change in operations and structure. Operations follow a sequential interdependency typical of logistical transformation, much as in manufacturing, one task following the other to produce a service output such

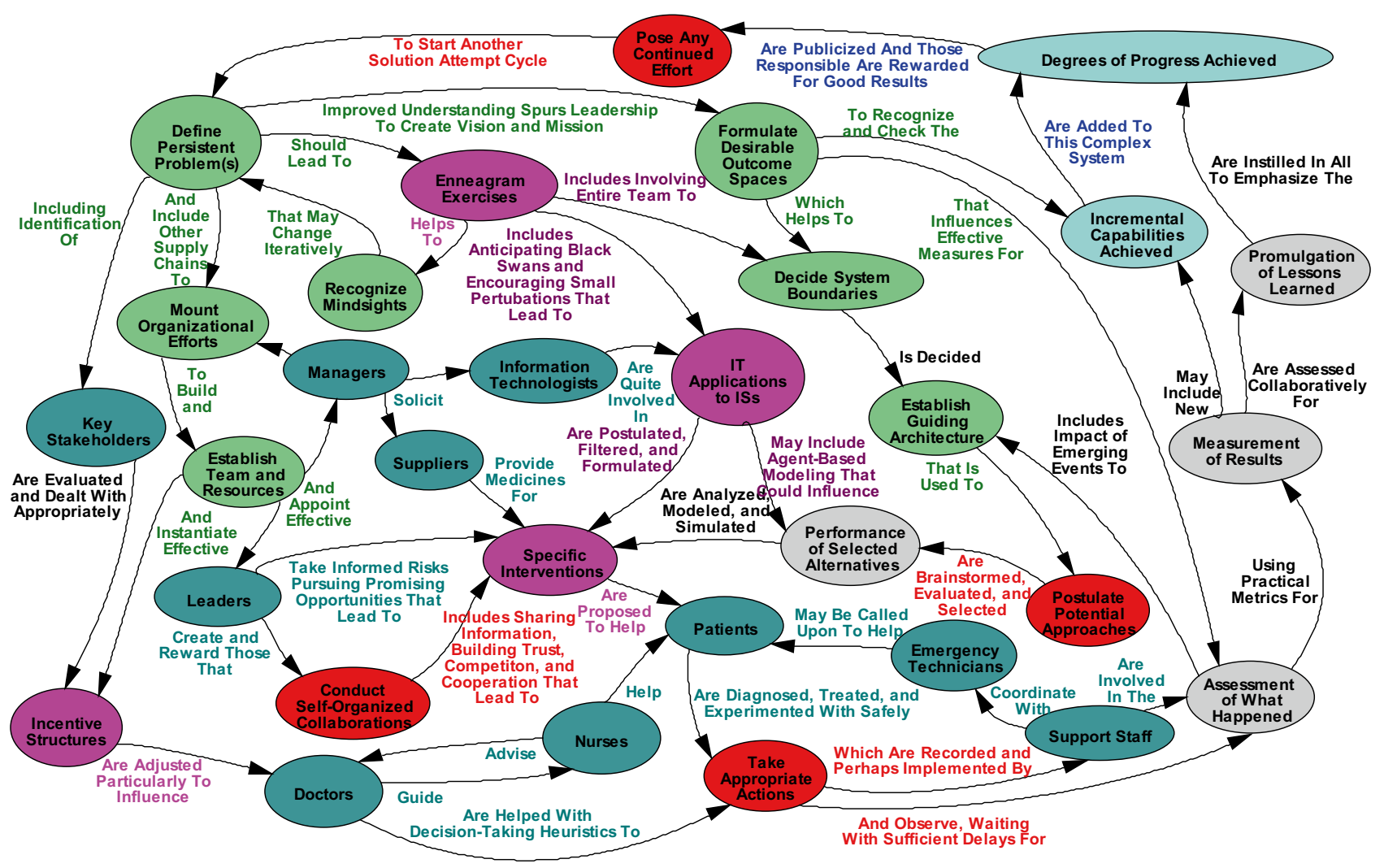

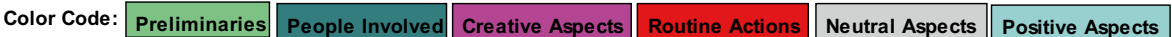

Fig. 9 The healthcare supply chain logistics domain. Suggested network, interdependencies and methodology 
as patient treatment. This sequentially in healthcare never follows a clean line. Networking produces healthcare services in an unruly environment. Organising in this setting is dependent on interaction. The healthcare actor therefore always perceives production as more or less uncertain. This is why healthcare as a complex service includes both pooled and reciprocal interdependency, because the decision-making has room for many options, and with increasing uncertainty, the agents are dependent on help from outside, increasing reciprocal interdependency. At the structural level, managing interdependencies through resource standardisation facilitates increased pooled interdependency, thereby economising interaction to produce the healthcare service. ISs represent a key resource in the transformation, the facilitation of increased pooled interdependency. Hand-in-hand with this effort, the IS facilitates improved sequential interdependency, evident as improved process traceability, informing about preceding operations, and tracking, knowing where various heterogeneous resources are currently to facilitate pooling. All this facilitates sending the patient onwards into the flow.

Interaction as "co-creation" in healthcare logistics services is conceptually important. Co-creation implies, following Thompson (1967), a power structure in the network characterized by reciprocal interdependency mutually adjusting through using intense technology to adapt through interaction in business relationships. It is a setting demanding an inter-subjective and therefore emergent understanding of the meaning of "production." The role of ISs here is to precisely support this process emergence in healthcare services. This involves: 1) data registration; 2) sharing of information on this emergent process's properties which, thereby, supports agency in sensemaking; and 3) managing this process in real time. A key attribute of such an IS, is connectivity through computer-human interfaces expressed as visualization techniques that interconnect different supply chain agents. This means seeking and implementing an ethically viable potential for automating agency, service provision interaction in a non-deterministic way.

Healthcare services need to be regarded as a complex system where human beings (in this case: patients, physicians, nurses, suppliers, and administrators) are pooled and reciprocally involved in providing and experiencing a variety of services and remedial treatments. Existing policies and procedures are oriented mainly toward helping sick people to get well instead of instituting incentives and rewards for keeping people healthy as the higher priority. Admittedly, migrating healthcare more toward the latter mindsight is largely in the domain of government legislative and institutional executive actions and beyond the scope of logistical supply chain improvements. But healthcare providers already have the power to take a more holistic approach in establishing improved methodologies that can facilitate, along with carefully selected information system technologies, more effective interpersonal communication and networked interactions among all parties and elements of this complex system. That is what has been emphasized and explored.

Most healthcare services are well-intentioned and at least partially effective, according to the literature, and direct observations of existing practices. However, it is also clear from interviews and analysis that systemic and systematic flaws significantly hinder higher quality healthcare, particularly in situations where time is a critical factor (e.g., in emergencies). Sure, one might prevent many emergencies by keeping people healthier, but as outlined above, that is not the way the system operates. So, taking a broader and more humanistic view of the technically-speaking logistical supply problem, leveraging pooled as well as reciprocal interactions, emphasizing additional attention to contingencies, and better applying information system technology are among the advocated principles to help caregivers deliver better services (their primary function) while alleviating their secondary administrative burdens.

\section{Concluding remarks}

The preceding conceptual modelling lays grounds for further investigation using simulation tools as supporting implementing new IT-supported healthcare processes through a continuous trial and error process. This implies also that the provided models may be refined based on such experiences. Since there is not yet a well-established and accepted theory that thoroughly considers the role of information in service chains when taking a complex systems perspective, further detailed case studies are of paramount importance in creating desirable outcomes. The processes need to be modelled enhancing features of process emergence. We really would like a better understanding of what works and what does not work in practice. Good case studies can significantly illuminate many issues. Three subcases, the: 1) logistical flow of commodities at a hospital; 2) waiting list paradox; and 3) emergency flow and inter-professional communication about patients moving between hospital and home care have been described and analysed. These should help set the stage for additional examples and more in-depth case studies in future work. The latter are certainly recommended, hopefully to be conducted as action research, meaning the research reports on process changes. Therefore, this substantiates reasons for reporting on trying out and sometimes failing in designing and using a healthcare service system from a complex systems approach.

Author contributions Per Engelseth is the coordinating author. He also contributed with theory on networks and contingencies. Brian E. White 
contributed with theory and analysis on complex systems. Duangpun Kritchanchai, Ingunn Mundal and Trude Fløystad Eines contributed with insights and theory on healthcare services management. They also wrote each one of the three cases presented in the paper.

Funding Open Access funding provided by UiT The Arctic University of Norway

\section{Compliance with ethical standards}

Conflict of interest The authors declare that they have no conflict of interest

Ethics approval and consent to participate This is a conceptual paper where the empirical part is based on examples. These examples are based on retrospective recollection of processes carried out by one of the authors in each of the three cases.

Open Access This article is licensed under a Creative Commons Attribution 4.0 International License, which permits use, sharing, adaptation, distribution and reproduction in any medium or format, as long as you give appropriate credit to the original author(s) and the source, provide a link to the Creative Commons licence, and indicate if changes were made. The images or other third party material in this article are included in the article's Creative Commons licence, unless indicated otherwise in a credit line to the material. If material is not included in the article's Creative Commons licence and your intended use is not permitted by statutory regulation or exceeds the permitted use, you will need to obtain permission directly from the copyright holder. To view a copy of this licence, visit http://creativecommons.org/licenses/by/4.0/.

\section{References}

1. Kritchanchai D. A framework for healthcare supply chain improvement in Thailand. J Operations Supply Chain Manag. 2012;5(2):103-13.

2. Lim PC, Tang NKH. A study of patients' expectations and satisfaction in Singapore hospitals. Int J Health Care Qual Assur. 2000;13(7):290-9.

3. Hall R. Patient Flow: Reducing Delay in Healthcare Delivery. Berlin: Springer; 2013.

4. Haszlinna MN, Potter A. Healthcare Supply Chain Management in Malaysia: A Case Study. Supply Chain Manag: Int J. 2009;4(3):234-43.

5. Leng CH. Medical Tourism and the State in Malaysia and Singapore. Global Social Policy. 2010;10(3):336-57.

6. Thompson JD. Organizations in Action. 1967; McGraw Hill, New York.

7. Kritchanchai D. A Roadmap towards Healthcare Logistics in Thailand. Proceedings of the 4th International Conference in Industrial Management Science and Applications. 2017; Seoul, Korea.

8. Engelseth, P., White BE. On People and Complexity in Healthcare Service Supply. Int J Des Nature Ecosystem. 13(3): 238-249.

9. Drach-Zahavy A, Somech A, Admc H, Peterfreund I, Peker H, Priente O. (How) do we learn from errors? A prospective study of the link between the ward's learning practices and medication administration errors. Int J Nurs Stud. 51(3): 448-457.

10. Ensing HT, Stuijt CCM, Van den Bemt BJF, Van Dooren AA, Karapinar-Çarkit F, Koster ES, Bouvy ML. Identifying the Optimal Role for Pharmacists in Care Transitions: A Systematic Review. J Manag Care Spec Pharm. 2015;21(8):614-36.
11. Kallio H, Pietilä A-M, Johnson M, Kangasniemi M. Systematic methodological review: Developing a framework for a qualitative semi-structured interview guide. J Adv Nurs. 2016;72(12):2954-65.

12. Kwan EX, Foss EJ, Tsuchiyama S, Alvino GM, Kruglyak L, Kaeberlei M, Raghuraman MK, Brewer BJ, Kennedy BK, Bedalov A. A Natural polymorphism in rDNA replication origins links origin activation with calorie restriction and lifespan. PLoS Genet. 2013;9(3):e1003329.

13. Blobel B, Lopez DM, Gonzalez C. Patient privacy and security concerns on big data for personalized medicine. Health Technology. 2016;6(1):75-81.

14. Kallio H, Pietilä AM, Johnsen M, Kangasniemi M. Systematic methodological review: Developing a framework for a qualitative semi-structured interview guide. J Adv Nurs. 2016;72(12):2954-65.

15. Verdoorn S, Kwint HF, Faber A, Gusseklo J, Bouvy ML. Majority of drug-related problems identified during medication review are not associated with STOPP/START criteria. Eur J Clin Pharmacol. 2015;71(10):1255-62.

16. Adhikari R, Tocher J, Smith P, Corcoran J, MacArthur J. A multi-disciplinary approach to medication safety and the implication for nursing education and practice. Nurse Educ Today. 2014;34(2):185-90.

17. Maher RL, Hanlon J, Hajjar ER. Clinical Consequences of Polypharmacy in Elderly. Expert Opin Drug Saf. 2014;13(1):57-65.

18. Willis JS, Jenkins WD, Kruse J, Bowre TS, Hoy RH. Home visits by trained undergraduate pre-health professional students: An extension of the patient-centered medical home. J Am Geriatr Soc. 2011;59(9):1756-7.

19. Palmer SC, Mavridis D, Navarese E, Craig JC, Tonelli M, Salanti G, Wiebe N, Ruospo M, Wheeler DC, Strippoli GFM. Comparative efficacy and safety of blood pressure-lowering agents in adults with diabetes and kidney disease: A network meta-analysis. The Lancet. 2015;385(9982):2047-56.

20. Liff R, Wickström E. The problem-avoiding multi professional team - On the need to overcome protective routines. Scand Manag J. 2014;30(3):282-91.

21. Melby L, Helles $\varnothing$ R. Introducing electronic messaging in Norwegian healthcare: Unintended consequences for interprofessional collaboration. Int J Med Informatics. 2014;83(5):343-53.

22. Parsons T. Structure and Processes in Modern Societies. Glencoe: The Free Press. IL; 1960.

23. Stabell CB, Fjeldstad ØD. Configuring Value for Competitive Advantage: On Chains, Shops, and Networks. Strateg Manag J. 1998;19(5):413-37.

24. Pfeffer J, Salancik G. The External Control of Organizations. 1978; Harper and Row, New York.

25. Leonardi PM. The Emergence of Materiality within Formal Organizations. In Carlile PR, Nicolai D, Langley A, Tsoukas H, How Matter Matters: Objects, Artifacts, and Materiality in Organization Studies. 2013; Oxford University Press Oxford, UK.

26. Spring M, Araujo L. Service, Services and Products: Rethinking Operations Strategy. Int J Prod Manag. 2009;29(5):444-67.

27. Chase R, Garvin D. The Service Factory. Harv Bus Rev. 1989;67(4):61-9.

28. Oliva R, Kallenberg R. Managing the transition from products to services. Int J Serv Ind Manag. 2003;14(2):160-72.

29. Weick KE, Sutcliffe KM, Obstfeld D. Organizing and the Process of Sensemaking. Organ Sci. 2005;16(4):409-21.

30. Grönroos C. Service management and marketing: managing the moments of truth in service competition, 1990; Lexington Books, Lexington MA.

31. Normann R. Reframing Business: When the Map Changes the Landscape. 2001; John Wiley \& Sons, West Sussex, UK. 
32. Sampson SE, Froehle CM. Foundations and Implications of a Proposed Unified Services Theory. Prod Oper Manag. 2006;15(2):329-43.

33. Bicheno J, Holweg M. The Lean Toolbox: The Essential Guide to Lean Transformation, 2009; PICSIE Books, Buckingham, UK.

34. Barad K. Ma(r)king time: Material entanglements and re-memberings: Cutting together-apart. In Carlisle PR, Nicolini D, Langley A, and Tsoukas H (Eds), How Matter Matters. 2013; Oxford University Press, Oxford, UK: 33.

35. Bandura A. Social cognitive theory: An agentic perspective. Annu Rev Psychol. 2001;52(1):1-26.

36. Lichtenstein BB. Generative Emergence. 2014; Oxford University Press, Oxford, UK: 54.

37. Juarrero A. Dynamics in Action: Intentional Behavior as a Complex System. 1999; MIT Press, Cambridge, MA.

38. Rzevski G, Skobelev P. Managing Complexity, 2014;WIT Press, Southhampton, UK: 5.

39. Carpintero JM, Garcia-Alonso J, Mäkitalo N, Murillo JM. From the Internet of Things to the Internet of People. IEEE Internet Comput. 2015;19(2):40-7.

40. Communications Logistics Specialists. The Internet of Things Leads to an Internet of Documents. 2017; Retrieved from https:// www.communication-logistics.com/Internet-of-Documents.html\#. WWJEyTOZO8U.

41. Harkness T. Big Data: Does Size Matter? 2016; Bloomsbury, New York.

42. Kuziemsky CE, Monkman H, Petersen C, Weber J, Borycki EM, Adams S, Collins S. Big Data in Healthcare: Defining the Digital Persona through User Contexts from the Micro to the Macro. Yearb Med Inform. 2014;9(1):82-9.

43. Engelseth P. Multiplex Uses of Food Product Standards. International Food and Agribusiness Management Review. 2013;16(2):75-94.

44. Kritchanchai D, Suwandechochai R. Supply Chain Management in Health Sector in Thailand: A Case Study. International Journal of Services, Economics and Management. 2010;2(2):211-24.

45. White BE. Fathoming the Future of Artificially Intelligent Robots. Int J Des Nat Ecodyn. 2018;13(1):1-15.
46. Priority Settings. Summary of a White Paper on Priority Setting in the Norwegian Health Care Sector, Norwegian Ministry of Health 2017and Care Services, Publication Number: I-1176 E, Norwegian Government Security and Service Organisation 02/2017, www. publikasjoner.dep.no

47. Gorod A, White BE, Ireland V, Gandhi SJ, Sauser BJ. Case Studies in System of Systems, Enterprise Systems, and Complex Systems Engineering. 2015; CRC Press, Taylor \& Francis Group. Boca Raton, FL.

48. Forrester JW. The Beginning of System Dynamics," Banquet Talk, International Meeting of the System Dynamics Society, 1989; Stuttgart, Germany, July 13, 1989, Retrieved from https://web. mit.edu/sysdyn/sd-intro/D-4165-1.pdf

49. Senge PM. The Fifth Discipline: The Art and Practice of the Learning Organization, 1990: Doubleday/Currency, New York.

50. Lee HL, Padmanabhan V, Whang S. The bullwhip effect in supply chains. Sloan Manag Rev. 1997;38(3):93-102.

51. Lee HL. Taming the Bullwhip. J Sup Chain Manag. 2010;46(1):7.

52. Boardman J, Sauser B. Systems Thinking: Coping with 21st Century Problems. 2008; CRC Press, Boca Raton, FL.

53. White BE. Complex Adaptive Systems Engineering. 8th Understanding Complex Systems Symposium, 2008; University of Illinois at Urbana-Champaign, IL, May 12-15. https://www.howhy. com/ucs2008/schedule.html

54. Knowles RN. The Leadership Dance: Pathways to Extraordinary Organizational Effectiveness, 3rd Edition, 2002; The Center for Self-Organizing Leadership, Niagara Falls, NY.

55. White BE. A Complex Adaptive Systems Engineering (CASE) Methodology: The Ten-Year Update. IEEE Systems Conference, 2016; Orlando, FL, April 18-21.

Publisher's Note Springer Nature remains neutral with regard to jurisdictional claims in published maps and institutional affiliations. 